\title{
Sequence Analysis and Expression of ORF5 in Korean Isolate of Porcine Reproductive and Respiratory Syndrome Virus
}

\author{
Sun Shin Yi ${ }^{1,4}$, Ji-Sun Sun ${ }^{1}$, Hyun-Soo Kim ${ }^{2}$, Shien-Young Kang ${ }^{3}$ and Tae-Wook Hahn ${ }^{{ }^{*}}$ \\ ${ }^{I}$ College of Veterinary Medicine and Institute of Veterinary Science, Kangwon National University, Chuncheon; \\ ${ }^{2}$ College of Veterinary Medicine, Chungnam National University, Daejeon; ${ }^{3}$ College of Veterinary Medicine, \\ Chungbuk National University, Cheongju, Korea; ${ }^{4}$ Department of Biomedical Sciences, College of Health Science, \\ Marquette University, Milwaukee, WI 53201, USA
}

Porcine reproductive and respiratory syndrome virus (PRRSV) is the causative agent of reproductive failure and respiratory disorders in pigs. The viral genome consists of eight overlapping open reading frames (ORFs). ORF5 encodes one of the major glycoproteins and is known as an immunologically important structural protein associated with virus neutralization. The ORF5 gene of the Korean PRRSV isolate, CNV-1, was amplified by reverse transcription-polymerase chain reaction (RT-PCR), cloned and sequenced. The nucleotide and amino acid sequences of CNV-1 ORF5 shared $91 \%$ and $83 \%$ identity, respectively, with the American isolate (VR2332 strain) and 57\% and $49 \%$ identity with the European isolate. For the expression and easy purification of ORF5, the cDNA containing the complete ORF5 sequence fused in-frame with sequence encoding glutathione $S$-transferase (GST) was cloned into a baculovirus transfer vector and transfected into $\mathrm{S} f 9$ cells. The GST-ORF5 fusion protein produced in $\mathrm{S} f 9$ cells was detected by sodium dodecyl sulfate-polyacrylamide gel electrophoresis and Western blotting. Sequencing results confirmed that the recombinant baculovirus from $\mathrm{S} f 9$ cells contains the complete ORF5 gene. Further studies in this direction will address whether ORF5 can be a good candidate for a subunit vaccine against PRRSV in Korea.

Key Words: Porcine reproductive and respiratory syndrome virus (PRRSV), CNV-1, Open reading frame 5 (ORF5), Recombinant baculovirus

\section{INTRODUCTION}

Porcine reproductive respiratory syndrome virus (PRRSV) is presently one of the most important infectious agents affecting the swine industry. The agent was first recognized in North America in 1987 and in Europe in 1990 (1, 2) and

Received: April 13, 2011/ Revised: June 15, 2011

Accepted: July 1, 2011

* Corresponding author: Tae-Wook Hahn, DVM, Ph.D. College of Veterinary Medicine, Kangwon National University, Chuncheon 200-701, Korea. Phone: +82-33-250-8671, Fax: +82-33-244-2367

e-mail: twhahn@kangwon.ac.kr

** This work was supported by grants from the Technology Development Program for Agriculture and Forestry, Ministry for Agriculture, Forestry and Fisheries and by the Institute of Veterinary Science, Kangwon National University, South Korea. characterized for causing severe reproductive and respiratory disorders (3). PRRSV was classified in the genus Arterivirus in family Arteriviridae (4). It consists of a plus-sense polyadenylated RNA genome $(15 \mathrm{~kb})$ which is surrounded by a cubical nucleocapsid core and a lipoprotein envelope, and the genome contains eight open reading frames (ORFs) $(5,6)$. ORF2, ORF3, and ORF4 encode envelope glycoproteins (GP 2, 3, and 4) with unknown functions, whereas ORF5 encodes a potentially antigenic envelope glycoprotein which is targeted by cellular immune response and is important for viral neutralization (7 10).

The American and European isolates, VR2332 and Lelystad virus (LV), respectively, show very high molecular and antigenic variations (11 14). These strains are so 
different in their genetic and antigenic characters that it is believed that they might belong to two distinct subpopulations originating from a common ancestor and may have evolved under the influence of local selective pressure (1). Accordingly, a conventional strategy for the control of PRRS depends strongly on immunization with a modified live vaccine (MLV) (Ingelvac ${ }^{\circledR}$ PRRS MLV, Boehringer Ingelheim, St. Joseph, USA) based on a cell-culture adaptation of the pathogenic North American VR2332 strain, which has been used since 1994. However, the efficacy and safety of the MLV have been studied by several groups (15 19), and the MLV has been found to have several disadvantages (20). To overcome these limitations, many new approaches for the development of second generation PRRS vaccines have been studied, including subunit vaccines, DNA vaccines, and so on (10). Among these vaccines, subunit vaccines have been proven to be safer and more effective than conventional vaccines (inactivated and live attenuated vaccines) (21). Recombinant PRRSV proteins have been expressed in several systems, such as $E$. coli (22), baculovirus (23 25), and Semliki forest virus (26). In the baculovirus expression system (BVES), the model virus is Autographa californica nuclear polyhedrosis virus (AcNPV), which was first isolated from the alfalfa looper (Autographa californica). It multiplies readily in cell lines derived from both the fall armyworm (Spodoptera frugiperda) and the cabbage looper (trichoplusiani). Over the last 25 years, BVES has become a very popular and effective means to produce recombinant proteins in large quantities. It might be convenient, therefore, to create fusion proteins by inserting well-defined epitopes of antigens derived from causative agents into baculovirus transfer plasmid vectors. Accordingly, many studies have recommended the ORF5 gene product as a good candidate for protection against PRRSV in spite of its high genetic diversity $(8,10,11,13,27,28)$.

In the present study, the ORF5 of the PRRSV Korean isolate (CNV-1) was cloned, sequenced, and examined for its genetic variability. With BVES, the ORF5 cDNA was cloned into a baculovirus transfer plasmid vector for homologous recombination with a linearized baculovirus
DNA. The recombinant baculoviruses were propagated on Spodoptera frugiperda clone 9 (S $f 9$ ) cells and the expressed recombinant ORF5 proteins were analyzed by sodium dodecyl sulfate-polyacrylamide gel electrophoresis (SDSPAGE) and Western blot analysis.

\section{MATERIALS AND METHODS}

\section{Cells and viruses}

The Korean PRRSV isolate, CNV-1, was propagated on MARC-145 cells grown in $\alpha$-minimal essential media ( $\alpha$-MEM) supplemented with 10\% fetal bovine serum (FBS) and $1 \times$ antibiotics and antimycotics (GIBCO-BRL, Grand Island, USA). The wild-type AcNPV, recombinant Xy1E and glutathione $S$-transferase (GST)-fused ORF5 recombinant baculoviruses were cultured in $\mathrm{S} f 9$ cells grown in TNM-FH media (Pharmingen, San Diego, USA) at $27^{\circ} \mathrm{C}$.

\section{RNA purification and reverse transcriptase (RT)-PCR}

Viral genomic DNA was extracted using TRIzol LS reagent (GIBCO-BRL, Paisley, Scotland) and reverse transcribed with the GeneAmp RNA PCR Core kit (Perkin Elmer, New Jersey, USA). Synthesis was carried out in a $50 \mu \mathrm{l}$ reaction mixture. For which $5 \mu \mathrm{l}$ of the extracted RNA was added to a reaction containing a final concentration of $2.5 \mathrm{mM} \mathrm{MgCl}_{2}, 1 \times$ PCR buffer $(50 \mathrm{mM} \mathrm{KCl}$ and $10 \mathrm{mM}$ Tris- $\mathrm{HCl}$ ), $0.1 \mathrm{mM}$ each deoxynucleotide triphosphate (dNTP), 1 unit of RNase inhibitor (GIBCO-BRL), 10 unit of reverse transcriptase (M-MLV; GIBCO-BRL) and 100 pmol of ORF5 reverse primer (5'-TT GAATTC CTA AGG ACG ACC CCA TTG-3': EcoRI restriction site is underlined). The mixture was placed in a PTC-100 thermocycler (MJ Research Inc., Watertown, USA) for one cycle at $57^{\circ} \mathrm{C}$ for $10 \mathrm{~min}, 42^{\circ} \mathrm{C}$ for $60 \mathrm{~min}, 95^{\circ} \mathrm{C}$ for $5 \mathrm{~min}$ and finally, the mixture was cooled at $4^{\circ} \mathrm{C}$. PCR was performed using $5 \mu \mathrm{l}$ of template cDNA from the previous RT-reaction in a $50 \mu \mathrm{l}$ total reaction volume. The reaction mixture for the PCR consisted of $1 \times$ PCR buffer, 50 pmol each of primer (forward primer: 5'-TT GGATCC ATG TTG GGG AAA TGC TTG-3', BamHI restriction site is underlined; reverse primer is described above), $0.1 \mathrm{mM}$ of each dNTP, $3 \mathrm{mM}$ 
$\mathrm{MgCl}_{2}$ and 1 unit Taq Plus polymerase (Bionics, Seoul, Korea). A hot start PCR technique was used to obtain specific amplification. The mixture was heated at $95^{\circ} \mathrm{C}$ for 4 min and then maintained at $82^{\circ} \mathrm{C}$, where 1 unit of Taq Plus polymerase was added. This step was followed by 35 programmed cycles as follows: DNA denaturation at $95^{\circ} \mathrm{C}$ for $30 \mathrm{sec}$, annealing at $55^{\circ} \mathrm{C}$ for $30 \mathrm{sec}$ and extension at $72^{\circ} \mathrm{C}$ for 45 sec. Finally, the mixture was incubated at $72^{\circ} \mathrm{C}$ for $10 \mathrm{~min}$. Following amplification, $10 \mu \mathrm{l}$ of the reaction mixture was electrophoresed in a $1 \%$ agarose gel (GIBCO-BRL), and the PCR product was visualized by staining with $10 \mathrm{mg} / \mathrm{ml}$ ethidium bromide.

\section{DNA Sequencing}

The amplified PCR fragments were gel purified with the GENECLEAN $^{\circledR}$ Turbo kit (BIO 101, Inc., Carlsbad, USA). The purified DNA was digested with BamHI and EcoRI and inserted into pUC19. The ligation mixture was transformed into E. coli Sure ${ }^{\circledR}$ cells (Stratagene, La Jolla, USA) by electroporation as described elsewhere (29). The recombinant plasmid DNA was purified from the transformants and confirmed by restriction enzyme digestion. Insertion of ORF5 into the recombinant plasmid was confirmed by nucleotide sequencing. The sequencing result was analyzed and compared with those of VR2332 and LV sequences obtained from GenBank (accession numbers U87392 and NC_002533, respectively) using DNASIS software, version 2.1 (Hitachi Software Engineering, Japan).

\section{Cloning of recombinant transfer vector}

The $\mathrm{pAcG} 2 \mathrm{~T}$ vector was used for the cotransfection with BaculoGold $^{\mathrm{TM}}$ DNA (Pharmingen). For cloning of the ORF5 cDNA into pAcG2T transfer vector, ORF5 and pAcG2T were digested with both BamHI and EcoRI, respectively. Both double digestion reaction products were then separated in a $1 \%$ agarose gel, purified with the GENECLEAN $^{\circledR}$ Turbo kit, and ligated using T4 DNA ligase. E. coli Sure ${ }^{\circledR}$ cells (Stratagene) were transformed with the ligation mixture and transformants were screened. Positive clones were selected by restriction enzyme digestion analysis and confirmed by direct sequencing.

\section{Generation of recombinant baculoviruses by co- transfection}

Recombinant baculovirus expressing the GST-ORF5 fusion protein were generated using the baculovirus expression kit purchased from Pharmingen. DNA of the recombinant pAcG2T transfer vector containing ORF5 was cotransfected with linearized baculovirus DNA (BaculoGold ${ }^{\mathrm{TM}}$ DNA, Pharmingen). For cotransfection, $2 \times$ $10^{6} \mathrm{~S} f 9$ cells from exponential growth were seeded into each of four $60-\mathrm{mm}$ diameter tissue culture plates. The cells were incubated at $27^{\circ} \mathrm{C}$ for $10 \mathrm{~min}$ to allow the cells to attach. Five hundred nanograms of BaculoGold ${ }^{\mathrm{TM}}$ DNA and $2 \sim 5 \mu \mathrm{g}$ of recombinant transfer vector were prepared in a microcentrifuge tube and the mixture was kept for $5 \mathrm{~min}$ before adding $1 \mathrm{ml}$ of Transfection Buffer B from the kit. The medium from each tissue culture plate was removed and was replaced with $1 \mathrm{ml}$ of Transfection Buffer A. The mixture of Transfection Buffer B and DNA in the microcentrifuge tube was added drop-wise to each plate containing the cells and then the plates was gently moved regularly backwards and forwards after the addition of every threeto-five drops.

Positive controls were co-transfected with $0.5 \mu \mathrm{g}$ of BaculoGold $^{\mathrm{TM}}$ DNA and $2 \mu \mathrm{g}$ of pVL1392-Xy1E control transfer vector DNA. Positive controls for wild-type baculovirus infection were infected with $1 \times 10^{6}$ plaque forming units (pfu) of wild-type AcNPV virus. The medium in noninfected negative control plates was removed and replaced with fresh TNM-FH medium. The plates cotransfected or infected with wild-type AcNPV were incubated at $27^{\circ} \mathrm{C}$ for $4 \mathrm{hr}$. The media was removed and fresh TNM-FH media was added and the plates were gently rocked. After the media was removed, fresh TNM-FH was added again and the cells were incubated at $27^{\circ} \mathrm{C}$ for 4 days. After five days, the supernatant and the cells of all four plates were collected separately. The supernatant was inoculated onto fresh $\mathrm{S} f 9$ cells for plaque assays.

\section{Plaque assays}

Plaque assays were performed to obtain the homologous 
recombinant baculovirus clone containing the recombinant ORF5 gene. S $f 9$ cells were prepared at $3 \times 10^{6}$ cells/plate and $60 \mu \mathrm{l}$ of serially diluted supernatant $\left(10^{0}, 10^{-1}, 10^{-2}\right.$, and $10^{-3}$ ) was inoculated onto cells. The plates were incubated at $27^{\circ} \mathrm{C}$ for $1 \mathrm{hr}$ to allow the virus to infect cells. During this time, Agarplaque-plus ${ }^{\mathrm{TM}}$ (Pharmingen) was dissolved in $2 \%$ in protein-free media by heating. Pre-cooled $2 \%$ agarose solution was mixed with the equal volume of pre-warmed $1 \times \mathrm{TNM}-\mathrm{FH}$ media resulting in a $1 \%$ agarose solution. The plates were overlaid with $5 \mathrm{ml}$ of $1 \%$ Agarplaque-plus ${ }^{\mathrm{TM}}$ solution. After the agar solution was solidified, the plates were incubated in a humid atmosphere at $27^{\circ} \mathrm{C}$. After ten days, plaques were picked with Pasteur pipettes and the virus particles were eluted from the agarose.

\section{Analysis of protein expression}

Baculovirus proteins were analyzed by discontinuous SDS-PAGE (5\% acrylamide stacking gel, 12\% acrylamide separating gel) (30). The cells were washed twice with phosphate-buffered saline (PBS). The samples (cells or supernatant) were mixed with $40 \mu$ of SDS-PAGE loading buffer containing $0.1 \mathrm{M}$ Tris (pH 6.8), 2\% SDS, 20\% glycerol, $8 \% \beta$-mercaptoethanol and bromophenol blue and heated at $55^{\circ} \mathrm{C}$ for $1 \mathrm{hr}$. Duplicate samples were analyzed for visualization by Coomassie blue staining and Western blot analysis.

For Western blotting, proteins were transferred to nitrocellulose membranes (Amersham Pharmacia Biotech, Buckinghamshire, England) using a transfer apparatus (BioRad, Hercules, USA). To confirm the transfer, membranes were stained with $0.1 \%$ Ponceau S (Sigma, Steinheim, Germany) before blocking. Next, the membranes were probed with swine anti-PRRSV serum or mouse anti-GST monospecific antibody (Pharmingen). For production of anti-PRRSV serum, two PRRSV-negative 70 day-old piglets were inoculated intranasally with $10^{4} \mathrm{TCID}_{50}$ of PRRSV (CNV-5). After 28 days post inoculation, the blood was collected and anti-PRRSV sera were prepared. Subsequently, the membranes were washed three times with TTBS (20 $\mathrm{mM}$ Tris, $500 \mathrm{mM} \mathrm{NaCl}, 0.05 \%$ Tween-20). Proteins were detected using horseradish peroxidase (HRP)-conjugated

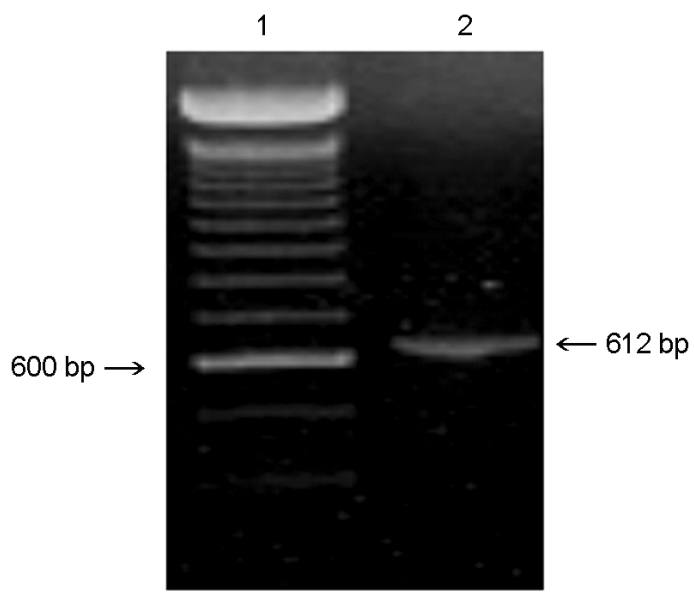

Figure 1. Amplification of CNV-1 ORF5. Lanes: 1, $100 \mathrm{bp}$ ladder; 2, CNV-1. The numbers on both sides indicate the size in bp.

rabbit anti-pig IgG (1:1,000; Sigma) or HRP-conjugated goat anti-mouse IgG (1:1,000; Sigma). After being washed, the membranes were developed using 4-chloro-1-napthol (Sigma).

\section{Confirmation of ORF5 in recombinant baculovirus}

In order to confirm the sequence of ORF5 in recombinant baculovirus, DNA was extracted from recombinant baculovirus by the phenol/chloroform method (31). The purified DNA was used as a template for PCR to amplify ORF5 as mentioned above. The PCR products were separated via electrophoresis in a 1\% agarose gel, gel extracted and cloned into pCR ${ }^{\circledR}$ 2.1-TOPO (Invitrogen, Carlsbad, USA) according to the manufacturer's instructions. Finally, the nucleotide sequence was determined.

\section{RESULTS}

\section{RT-PCR and sequence analysis}

A 612 bp ORF5 gene product from CNV-1 was obtained by RT-PCR (Fig. 1). Since the PCR product had BamHI and EcoRI sites at either end, the PCR product was cloned into the BamHI-EcoRI site of pUC19, and the nucleotide sequences of ORF5 were determined and amino acid sequence were deduced from the nucleotide sequence Nucleotide and amino acid sequences of the CNV-1 ORF5 showed $91 \%$ and $83 \%$ homology, respectively, with the 
North American strain VR2332, whereas they showed only $57 \%$ and $49 \%$ homology, respectively, with the European isolate, LV (Fig. 2). Nucleotide and amino acid changes were distributed all over the sequenced region and no significant deleted regions were observed. Amino acid sequencing showed that CNV-1 and LV had two $N$-glycosylation sites, whereas VR2332 had three $N$-glycosylation sites (Fig. 2B).

\section{Co-transfection and morphology of S $f 9$ cells}

$\mathrm{S} f 9$ cells are known to grow well both in suspension and as monolayer cultures. Upon transfection and infection, $\mathrm{S} f 9$ cells appeared much larger than uninfected cells and had many occlusion bodies in their nuclei (data not shown). Each occlusion body was found to be surrounded by a polyhedral envelope. The infected $\mathrm{S} f 9$ cells stopped dividing and were found floating in the medium. The optimal collection time for recombinant baculovirus, wild-type AcNPV and recom-

(A)

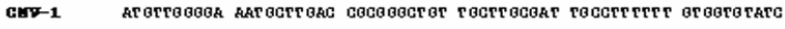
a

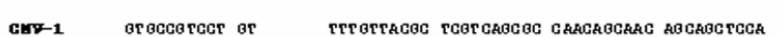

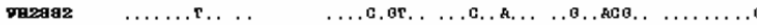

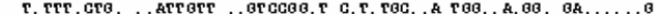

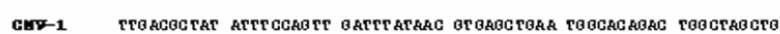

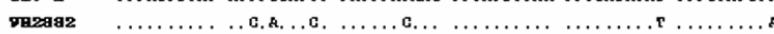

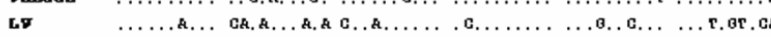

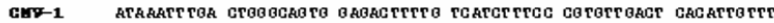
c.

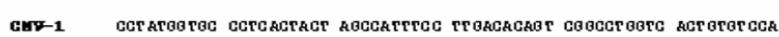

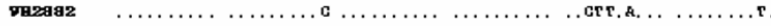
, AC

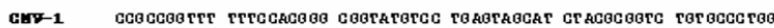

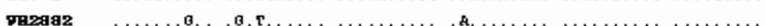

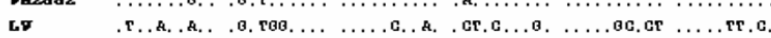

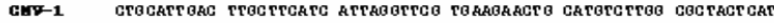

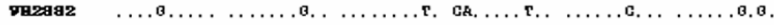

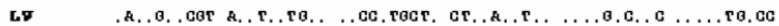

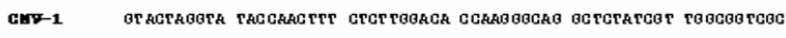

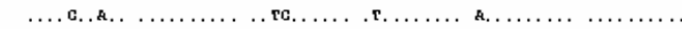

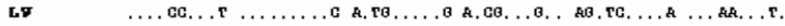

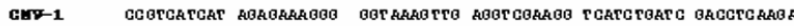

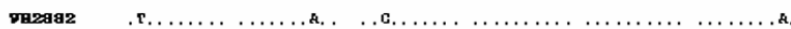

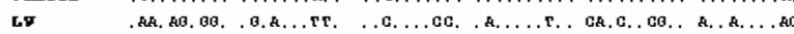

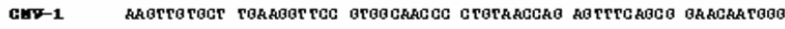

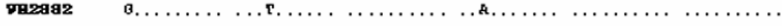

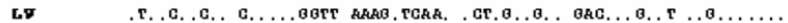

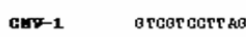

THzage $\quad \ldots \ldots \ldots \ldots$ binant Xy1E positive controls was 96 120 hrs postinfection.

\section{Analysis of recombinant ORF5 expression}

S $f 9$ cells were infected with each of the following recombinant baculoviruses: GST-ORF5, wild-type AcNPV, and recombinant XylE positive controls. Infected cells were incubated at $27^{\circ} \mathrm{C}$ for four days post-infection. Expression of ORF5 was analyzed by electrophoresis in 12\% SDSpolyacrylamide gels. To determine the location of the recombinant ORF5 protein, the supernatants and cell pellets were analyzed individually. By Coomassie blue staining, it was difficult to detect the presence of extra bands corresponding to recombinant proteins over the background of the cell pellets (data not shown). Moreover, only one band was present in the supernatant, which did not correspond with the expected size. For this reason, it was necessary to

B

Figure 2. Nucleotide sequences (A) and amino acid sequences (B) of CNV-1 ORF5 compared with those of VR2332 (accession number U87392) and LV (accession number NC 002533). Underlines indicate putative $N$ glycosylation sites. 
A

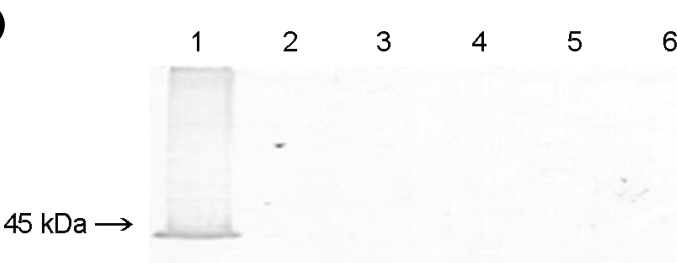

B

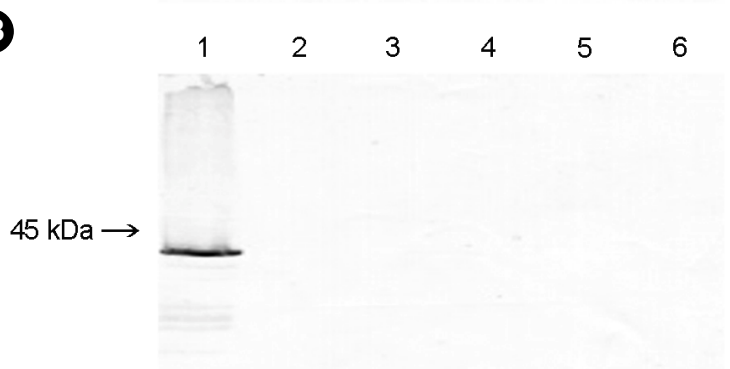

Figure 3. Analysis of protein expression by Western blottings probed with swine anti-PRRSV serum (A) and mouse anti-GST monospecific antibody (B). The supernatants and the cell pellet were harvested at four days post-infection and were separated by SDS-PAGE, then transferred to nitrocellulose membranes. The proteins were detected with peroxidase-labeled anti-pig IgG (A) and peroxidase-labeled anti-mouse $\operatorname{IgG}(\mathrm{B})$. Lanes: 1, lysate of $\mathrm{S} f 9$ cells infected with recombinant baculovirus containing ORF5; 2 , lysate of $\mathrm{S} f 9$ cells infected with wild-type AcNPV; 3 , lysate of S $f 9$ cells infected with recombinant Xy1E; 4, supernatant of S $f 9$ cells infected with recombinant baculovirus containing ORF5; 5, supernatant of $\mathrm{S} f 9$ cells infected with wild-type AcNPV; and 6, lysate of non-infected $\mathrm{S} f 9$ cells. The numbers at the left indicate size markers.

confirm the expression of GST-ORF5 by Western blotting with swine anti-PRRSV serum or anti-GST monospecific antibody. The results showed that only single band was detected in cell lysates of $\mathrm{S} f 9$ cells infected with recombinant baculovirus containing ORF5 (Fig. 3). The expected size of ORF5 fused with GST is around $51.5 \mathrm{kDa}(26.5 \mathrm{kDa}$ of GST plus $25 \mathrm{kDa}$ of ORF5). However, the size of the detected protein was slightly below $45 \mathrm{kDa}$ (about $44 \mathrm{kDa}$ ), which would be the non-glycosylated form of ORF5.

Confirmation of ORF5 nucleotide sequence in the recombinant baculovirus

To confirm whether the ORF5 gene from the recombinant baculovirus was intact or not, DNA was extracted from the recombinant baculovirus containing ORF5 and a PCR were carried out as previously described. The purified $612 \mathrm{bp}$
PCR product was recovered from the gel and cloned into $\mathrm{pCR}^{\circledR}$ 2.1-TOPO (Invitrogen). DNA sequence analysis of the PCR product revealed $100 \%$ identity of the nucleotides to those of CNV-1 as described in Fig. 2.

\section{DISCUSSION}

Since the first outbreak of PRRS reported in 1993, swine farms in Korea have persistently suffered from economic loss owing to abortion and respiratory distress. Unfortunately, the efficacy of the PRRS vaccine has been controversial, and the control programs against PRRS in Korea have yet not been effective in prevention. In an attempt to address these problems, ORF5 of the Korean PRRSV isolate, which encodes an envelope protein, was amplified, sequenced, cloned and expressed in a baculovirus expression system. ORF5 was chosen from among the PRRSV proteins because protection mediated by anti-ORF5 antibodies has been reported (10) and presumably, this protein is the main envelope glycoprotein of PRRSV. In fact, ORF5 of PRRSV should be equivalent to ORF5 of equine arteritis virus (EAV), a virus that is closely related to PRRSV. Importantly, antibodies to EAV ORF5 neutralize viral infectivity (32). In addition, pigs immunized with plasmid DNA encoding ORF5 produced specific neutralizing antibodies and a cellular immune response, thus protecting the vaccinated pigs from viremia and the development of typical macroscopic lung lesions (10).

Several studies have reported a high degree of antigenic and genetic diversity between the American and European PRRSV isolates $(8,12,33,34)$. ORF5 has been found to be the most variable protein, with only $51 \sim 55 \%$ amino acid sequence identity between American and European isolates $(12,35)$. ORF5 also showed the highest degree of diversity within one genotype (87.1 99.2\% identity among European isolates and $85 \sim 99 \%$ identity among American isolates) (14). In this study, the ORF5 nucleotide and amino acid sequences of the Korean isolate, CNV-1, showed $91 \%$ and $83 \%$ homologies, respectively, with those of VR2332, the American strain; however, they showed only $57 \%$ and $49 \%$ homologies, respectively, with those of LV, the European 
strain. This result indicates that Korean PRRSV isolates, including CNV-1, are more closely related to American strains. The reason for the genetic variation in ORF5 might be immunological pressures on ORF5 gene product located at the surface of the virus (23). Consequently, it is important to develop vaccines that are highly homologous to the prevalent PRRSV types in the area or country, and these vaccines should be tested for their ability to protect against the field PRRSV isolates in the area.

Recombinant baculovirus containing the ORF5 genes of PRRSV was constructed and used to express the protein in $\mathrm{S} f 9$ insect cells. The protein was detected by both Coomassie blue staining of gels and Western blotting using porcine anti-PRRSV sera. Because ORF5 was fused with GST to facilitate purification, the GST-ORF5 fusion protein could also detected by Western blotting using anti-GST monospecific antibody. Although ORF5 was correctly inserted in the baculovirus transfer vector and in recombinant baculovirus, the size of the expressed GST-fused ORF5 protein was slightly smaller than the expected size from the deduced amino acid sequences. This could be due to abnormal migration of the GST-fused protein during SDSPAGE, proteolysis in sample preparation, nonglycosylated form of ORF5 and so on. In a previous study, recombinant ORF5 expressed in baculovirus system showed at least 3 forms of proteins with different size $(20,25,26 \mathrm{kDa})$ and the nonglycosylated form of ORF was around $20 \mathrm{kDa}(25)$. In this study, the band shown in Western blotting was the band in similar size and reactivity shown in the previous study (10). Additionally, the small protein seen later may be an amino-terminally truncated form of the full-length $51.5 \mathrm{kDa}$ protein or is encoded by an mRNA that initiates from a downstream transcription start site located within the ORF (36). However, further study should be undertaken to determine the exact origin of this small moiety.

Unexpectedly, only single polypeptide was found to be reactive to porcine hyper-immune sera in $\mathrm{S} f 9$ cells infected with recombinant baculovirus containing ORF5. In Western immunoblots for ORF5 of the VR2332 and LV strains, several polypeptide forms were detected, which are glycosylated forms and might be functional in vivo. Previous studies have shown that VR2332 has three $N$-glycosylation sites in contrast to two $N$-glycosylation sites of $\operatorname{LV}(35,37)$. These findings are in accordance with those from the deduced amino acid sequences shown in Fig. 2. Even the ORF5 of CNV-1 has two putative $N$-glycosylation sites from the deduced amino acid sequences, but only one polypeptide was detected in Western blots (Fig. 3), which might be a non-glycosylated form. In order to confirm that the BVES used in this study functions correctly, ORF5 of VR2332 should be cloned into it and expressed in the same insect cells. Otherwise, the different BVESs purchased from other companies could be used to obtain glycosylated forms of CNV-1 ORF5.

In summary, we amplified ORF5 of the Korean PRRSV isolate, cloned and expressed fused proteins in a baculovirus expression system. In future, the purified ORF5 protein of CNV-1 should be tested for its ability to confer protection against Korean field isolates by challenge studies and may be the major candidate for the final development of a subunit PRRSV vaccine.

\section{REFERENCES}

1) Albina E. Epidemiology of porcine reproductive and respiratory syndrome (PRRS): an overview. Vet Microbiol 1997;55:309-16.

2) Wootton SK, Nelson EA, Yoo D. Antigenic structure of the nucleocapsid protein of porcine reproductive and respiratory syndrome virus. Clin Diagn Lab Immunol 1998;5:773-9.

3) Lunney JK, Benfield DA, Rowland RR. Porcine reproductive and respiratory syndrome virus: an update on an emerging and re-emerging viral disease of swine. Virus Res 2010;154:1-6.

4) Cavanagh D. Nidovirales: a new order comprising Coronaviridae and Arteriviridae. Arch Virol 1997;142: 629-33.

5) Conzelmann KK, Visser N, van Woensel P, Thiel HJ. Molecular characterization of porcine reproductive and respiratory syndrome virus, a member of the arterivirus group. Virology 1993;193:329-39.

6) Meulenberg JJ, Hulst MM, de Meijer EJ, Moonen PL, 
den Besten A, de Kluyver EP, et al. Lelystad virus, the causative agent of porcine epidemic abortion and respiratory syndrome (PEARS), is related to LDV and EAV. Virology 1993;192:62-72.

7) Cha SH, Choi EJ, Park JH, Yoon SR, Song JY, Kwon $\mathrm{JH}$, et al. Molecular characterization of recent Korean porcine reproductive and respiratory syndrome (PRRS) viruses and comparison to other Asian PRRS viruses. Vet Microbiol 2006;31:248-57.

8) Indik S, Valícek L, Klein D, Klánová J. Variations in the major envelope glycoprotein GP5 of Czech strains of porcine reproductive and respiratory syndrome virus. J Gen Virol 2000;81:2497-502.

9) Kiss I, Sámi L, Kecskeméti S, Hanada K. Genetic variation of the prevailing porcine respiratory and reproductive syndrome viruses occurring on a pig farm upon vaccination. Arch Virol 2006;151:2269-76.

10) Pirzadeh $B$, Dea $S$. Immune response in pigs vaccinated with plasmid DNA encoding ORF5 of porcine reproductive and respiratory syndrome virus. J Gen Virol 1998;79:989-99.

11) Goldberg TL, Hahn EC, Weigel RM, Scherba G. Genetic, geographical and temporal variation of porcine reproductive and respiratory syndrome virus in Illinois. $\mathrm{J}$ Gen Virol 2000;81:171-9.

12) Kapur V, Elam MR, Pawlovich TM, Murtaugh MP. Genetic variation in porcine reproductive and respiratory syndrome virus isolates in the midwestern United States. J Gen Virol 1996;77:1271-6.

13) Okuda Y, Kuroda M, Ono M, Chikata S, Shibata I. Efficacy of vaccination with porcine reproductive and respiratory syndrome virus following challenges with field isolates in Japan. J Vet Med Sci 2008;70:1017-25.

14) Pirzadeh B, Gagnon CA, Dea S. Genomic and antigenic variations of porcine reproductive and respiratory syndrome virus major envelope GP5 glycoprotein. Can J Vet Res 1998;62:170-7.

15) Mengeling WL, Lager KM, Vorwald AC. Safety and efficacy of vaccination of pregnant gilts against porcine reproductive and respiratory syndrome. Am J Vet Res 1999;60:796-801.

16) Cano JP, Dee SA, Murtaugh MP, Pijoan C. Impact of modified-live porcine reproductive and respiratory syndrome virus vaccine intervention on a population of pigs infected with a heterologous isolate. Vaccine 2007;25:4382-91.

17) Nielsen HS, Oleksiewicz MB, Forsberg R, Stadejek T, Bøtner A, Storgaard T. Reversion of a live porcine reproductive and respiratory syndrome virus vaccine investigated by parallel mutations. J Gen Virol 2001; $82: 1263-72$

18) Thanawongnuwech R, Halbur PG, Ackermann MR, Thacker EL, Royer RL. Effects of low (modified-live virus vaccine) and high (VR-2385)-virulence strains of porcine reproductive and respiratory syndrome virus on pulmonary clearance of copper particles in pigs. Vet Pathol 1998;35:398-406.

19) Wesley RD, Mengeling WL, Lager KM, Clouser DF, Landgraf JG, Frey ML. Differentiation of a porcine reproductive and respiratory syndrome virus vaccine strain from North American field strains by restriction fragment length polymorphism analysis of ORF 5. J Vet Diagn Invest 1998;10:140-4.

20) Cano JP, Dee SA, Murtaugh MP, Pijoan C. Impact of a modified-live porcine reproductive and respiratory syndrome virus vaccine intervention on a population of pigs infected with a heterologous isolate. Vaccine 2007; 25:4382-91

21) Tacket CO, Losonsky G, Lubeck MD, Davis AR, Mizutani S, Horwith G, et al. Initial safety and immunogenicity studies of an oral recombinant adenohepatitis B vaccine. Vaccine 1992;10:673-6.

22) Kwang J, Zuckermann F, Ross G, Yang S, Osorio F, Liu W, et al. Antibody and cellular immune responses of swine following immunisation with plasmid DNA encoding the PRRS virus ORF's 4, 5, 6 and 7. Res Vet Sci 1999;67:199-201.

23) Plana Duran J, Climent I, Sarraseca J, Urniza A, Cortés E, Vela C, et al. Baculovirus expression of proteins of porcine reproductive and respiratory syndrome virus strain Olot/91. Involvement of ORF3 and ORF5 proteins in protection. Virus Genes 1997;14:19-29.

24) Koo HN, Oh JM, Lee JK, Choi JY, Lee KS, Roh JY, et al. Molecular characterization of ORFs 2 to 7 of Korean porcine reproductive and respiratory syndrome virus (CA) and its protein expression by recombinant baculoviruses. J Microbiol 2008;46:709-19.

25) Kreutz LC, Mengeling WL. Baculovirus expression and 
immunological detection of the major structural proteins of porcine reproductive and respiratory syndrome virus. Vet Microbiol 1997;59:1-13.

26) Jung HS, Hwang IW, Kim SM, Kim CJ, Shin KS, Kim HS. Expression of open reading frame 5 protein of porcine reproductive and respiratory syndrome virus using semliki forest virus expression system. J Vet Sci 2002;3:13-8.

27) Li Y, Wang X, Jiang P, Chen W, Wang X. Genetic analysis of two porcine reproductive and respiratory syndrome viruses with different virulence isolated in China. Arch Virol 2008;153:1877-84.

28) Nam E, Park CK, Kim SH, Joo YS, Yeo SG, Lee C. Complete genomic characterization of a European type 1 porcine reproductive and respiratory syndrome virus isolate in Korea. Arch Virol 2009;154:629-38.

29) Calvin NM, Hanawalt PC. High-efficiency transformation of bacterial cells by electroporation. J Bacteriol 1988;170:2796-801.

30) Laemmli UK. Cleavage of structural proteins during the assembly of the head of bacteriophage T4. Nature 1970;227:680-5.

31) Le CT, Gray GC, Poddar SK. A modified rapid method of nucleic acid isolation from suspension of matured virus: applied in restriction analysis of DNA from an adenovirus prototype strain and a patient isolate. $\mathrm{J}$ Med Microbiol 2001;50:571-4.

32) Balasuriya UB, Timoney PJ, McCollum WH, Mac-
Lachlan NJ. Phylogenetic analysis of open reading frame 5 of field isolates of equine arteritis virus and identification of conserved and nonconserved regions in the GL envelope glycoprotein. Virology 1995;214: 690-7.

33) Fang Y, Schneider P, Zhang WP, Faaberg KS, Nelson EA, Rowland RR. Diversity and evolution of a newly emerged North American Type 1 porcine arterivirus: analysis of isolates collected between 1999 and 2004. Arch Virol 2007;152:1009-17.

34) Meng XJ, Paul PS, Halbur PG, Morozov I. Sequence comparison of open reading frames 2 to 5 of low and high virulence United States isolates of porcine reproductive and respiratory syndrome virus. J Gen Virol 1995;76:3181-8.

35) Murtaugh MP, Elam MR, Kakach LT. Comparison of the structural protein coding sequences of the VR-2332 and Lelystad virus strains of the PRRS virus. Arch Virol 1995;140:1451-60.

36) Wu X, Stewart S, Theilmann DA. Alternative transcriptional initiation as a novel mechanism for regulating expression of a baculovirus trans activator. J Virol 1993; 67:5833-42.

37) Mardassi H, Mounir S, Dea S. Molecular analysis of the ORFs 3 to 7 of porcine reproductive and respiratory syndrome virus, Québec reference strain. Arch Virol 1995;140:1405-18. 